likelihood of generating abuse. Doctors need to be able to understand and contribute to the management of the aggressive patient, the demanding patient or the one no-one likes, and to appreciate the importance of appropriate sexuality in continuing care settings and the management of conflict between staff and patients.

\section{Policy}

A number of recent initiatives from the NHS (e.g. clinical governance), and more widely from the Department of Health (2000, 2001), may prompt the development of policies to end the abusive practices that have been recognised. However, effective change is more likely when demonstrated and led by senior staff with an understanding of themselves and their own reactions, an understanding of staff at all levels and the personal and professional difficulties they face and an imaginative understanding of what it must be like for the older person to live in one of the homes or wards to which they are subjected. In this doctors have a major role.

\section{Conclusion}

Older people should not be seen only as potential victims. However, patients in institutions are vulnerable through mental incapacity, physical frailty and dependency. They are the most likely to fall prey to dehumanising attitudes. Institutional abuse of older people is common, insidious and a serious indictment of the caring professions, including medicine. Aetiological factors are multiple, complex and deep-rooted but individual responsibilities are clear. Old age psychiatrists' daily work brings them into intimate contact with the difficulties inherent in caring for disabled and dependent older people and the ambivalent feelings that this evokes. They are in a position to understand and influence the institutions with which they are in contact, and have a duty to do so. Since the enquiry into the death of Stephen Lawrence (Macpherson, 1999), institutions are being invited to examine individual and collective racism. Old age psychiatrists have a responsibility to take the lead in prompting an examination of ageism and the capacity for abuse in the homes and wards where they work. 'Patients must be able to trust doctors with their lives and wellbeing' (General Medical Council, 1995).

\section{Acknowledgements}

This paper was commissioned by the Ethics Subcommittee. It is based on work prepared for the Faculty of Old Age Psychiatry that subsequently became Council Report CR84 (Royal College of Psychiatrists, 2000).

\section{References}

AUDIT COMMISSION (2000) Forget me Not: Mental Health Services for Older People. London: Audit Commission.

BAYER, A. \& TADD, W. (2000) Unjustified exclusion of olderly people from studies submitted to research ethics committee for approval: descriptive study. British Medical Journal, 321, 992-993.

DEPARTMENT OF HEALTH (2000) No Secrets. London: Department of Health.

— (2001) National Service Framework for Older People. London: Department of Health.

EVANS, S. (1998) Beyond the mirror: a group analytic exploration of late life and depression. Aging and Mental

Health, 2, 94-99.

GARNER, J. \& ARDERN, M. (1998) Reflections on old age. Aging and Mental Health, 2, 92-93.

GENERAL MEDICAL COUNCIL (1995) Duties of a Doctor. London: General Medical Council.

GLENDENNING, S. (1997) The mistreatment and neglect of elderly people in residential centres: research outcomes in the mistreatment of elderly people. InThe Mistreatment of Elderly People (2nd edn) (eds P. Decalmer \& S. Glendenning), pp.151162. Newbury Park, CA: Sage Publications.

GOFFMAN, E. (1961) Asylums: Essays on the Social Situation of Mental Patients and Other Inmates. New York: Doubleday.

KITWOOD,T. (1990) The dialectics of dementia: with particular reference to Alzheimer's disease. Ageing in Society, 10, 177-196.

MCGRATH, A. M. \& JACKSON, G. A (1996) Survey of neuroleptic prescribing in residents of nursing homes in Glasgow. British Medical Journal, 312, 611-612.

MACPHERSON, W. (1999) The Stephen Lawrence Enquiry. London: HMSO.

MAIN,T. F. (1957) The ailment. Medical Psychology, 30(129), 0-145.

ROYAL COLLEGE OF PSYCHIATRISTS (2000) Institutional Abuse of Older Adults. Council Report CR84. London: Royal College of Psychiatrists.

TERRY, P. (1997) Counselling the Elderly and their Carers. Basingstoke: Macmillan.

— (1998) Who will care for older people? A case study of working with destructiveness and despair in long stay care. Journal of Social Work Practice, 12(2), 209-216.

WARDHAUGH, J. \& WILDING, P. (1993) Towards an explanation of the corruption of care. Critical Social Policy, 37(13), 4-31.

WINNICOTT, D. (1949) Hate in the countertransference. International Journal of Psychoanalysis, 30, 69-74.

*Jane Garner Consultant in Old Age Psychiatry, Chase Farm Hospital, Enfield EN2 8JL, *Sandra Evans Consultant and Senior Lecturer in Old Age Psychiatry, St Bartholomew's and Homerton Hospital

LUKE BIRMINGHAM AND MARTIN S. HUMPHREYS

\title{
Practical and legal aspects of withholding patients' mail
}

There are a number of different clinical circumstances in which the issue of incoming and outgoing mail to or from a patient in a psychiatric hospital, whether detained or not, may present particular difficulties. Under current mental health legislation there is provision for post to be stopped or inspected on clinical and legal grounds (Jones, 1999), but these are fairly limited and concern only outgoing mail in specific circumstances, other than for patients detained in special hospitals (Mental Health Act (MHA) 1983). The issue of patients' mail may lead to 
problems in day-to-day practice where patients' desire to send or receive correspondence is linked to their abnormal mental state, is a direct result of symptoms of their illness or when it might constitute a potential or actual criminal offence. This paper reviews the relevant part of the MHA 1983 and describes three case vignettes that illustrate some of the difficulties and potential solutions to problems associated with patients' correspondence.

\section{Mental Health Act}

Part X of the MHA 1983 deals with miscellaneous provisions, one of which, at Section 134, concerns the correspondence of patients. Broadly it states that in certain specific circumstances patients' mail, either incoming or outgoing, may be withheld. This applies to detained patients only (Gostin, 1986). There is no statutory power to interfere with informal patients' mail. A 'postal packet', the term used in the Act, is 'a letter, postcard, reply postcard, newspaper, printed packet, sample packet, or parcel, and every packet or article transmissible by post, and includes a telegram' (Post Office Act 1953). Correspondence between a patient and certain individuals and bodies may not be withheld or opened. These are listed in Box 1.

\section{Section 134}

\section{Incoming mail}

Authority to withhold incoming mail addressed to a patient detained in hospital provided under Section 134 of the MHA 1983 only applies in the case of patients in a special hospital. Under such circumstances this step may be justified if, in the opinion of the managers of the hospital, it is necessary to do so in the interests of the safety of the patient or for the protection of others (Department of Health and Welsh Office, 1999).

\section{Outgoing mail}

In a special hospital the managers may withhold a postal packet from dispatch when they consider that it may cause distress to the addressee or an individual other than staff at the hospital (Section 134(1) (b) (i)) or where it might cause 'danger to any person' (Section 134(1) (b) (ii)). In all other circumstances, where patients are detained elsewhere, correspondence can only be prevented under the MHA from being posted where the person to whom it is addressed has requested in writing to the managers of the hospital, the responsible medical officer or the Secretary of State, that it be withheld (Section 134(1) (a)).

Hospital managers are entitled, under Section 134, sub-section (4) to inspect and open packages to see if they do fulfil the criteria for being withheld from patients or from being dispatched. If an item is withheld the person nominated to represent the hospital manager is obliged to keep a written record of the fact. Where
Box 1 Individuals or bodies from whom patients' postal packets may not be withheld

Patients' legal representative

Hospital managers

Mental health review tribunal

Health or local social services authority

Community Health Council

Probation or After-care Committee

Minister of the Crown

Member of Parliament

Member of the House of Lords

Officer of the Court of Protection

Lord Chancellor's visitor

Parliamentary Commission for Administration

Health Services Commissioner for England or Wales

Local Commissioner under the Local Government Act 1974

European Commission

European Court of Human Rights

outgoing mail is withheld at a special hospital the patient must be informed in writing within 7 days. In the case of an incoming packet the patient and sender must be informed likewise. Under Section 121 (7) of the MHA 1983, the MHA Commission may review any decision to withhold a postal packet sent by or to a special hospital patient, where the patient or the sender makes an application to them. Where appropriate they may then direct that the decision to withhold it should be reversed. There is similar provision to that described above under Section 115 of the Mental Health (Scotland) Act 1984.

It may be that the patient's preoccupation with letter writing or receiving correspondence could be considered positively detrimental to his/her mental state. In such circumstances it may be appropriate to consider withholding correspondence as part of the treatment plan in the patient's best interests.

\section{Common law}

There may be circumstances where it could be deemed appropriate and legal to withhold or interrupt the passage of mail sent into or out of a hospital. One such example would be where allowing passage of a letter or parcel might be a criminal offence or make the admission of such an offence likely.

\section{Case illustrations}

\section{Case one}

Mrs J. was detained on a hospital order. She had been convicted of harassment. Mrs J. had a delusional disorder. A restraining order had previously been imposed to prevent her trying to establish contact with the various victims of her original offences. She did not believe that they wanted nothing more to do with her. She had not been deterred from continuing to write to several of them, even when briefly remanded in custody. Some of those concerned wrote to the hospital managers stating that they did not wish to receive correspondence from 
her. In the light of this Mrs J.'s outgoing post was monitored and all that addressed to the victims was withheld but left unopened. Mrs J. was informed. Lawful power to withhold post was provided by the MHA 1983 at Section 134 (1) (a) and also under the conditions of the original restraining order.

In this case the action to be taken on the part of the clinical team was obvious. There had already been contact with the victims of the previous offences and most had been informed of her whereabouts. Those who did receive mail from her, once she had been admitted to hospital, telephoned to inform staff on the unit where she was resident and were advised of the correct procedure for writing to the hospital managers so that any further mail could be withheld.

\section{Case two}

Mrs W. was a 48-year-old woman detained on a civil treatment order. She had a chronic psychotic illness. Mrs $W$. was a prolific letter writer, although she seldom corresponded with the same person more than once. Letters written to others often reflected her severely disturbed state of mind. In order to manage the situation Mrs W.'s access to stationery was restricted. Packages addressed to people who had specifically requested not to receive mail were withheld and stored unopened under Section 134 (1) (a) of the MHA 1983. Some outgoing mail to people with whom she had had no previous contact and certain incoming packets were withheld unopened on the grounds that it was in the interests of Mrs W.'s own health to do so.

Here something of the clinical dilemma emerged in that Mrs W. was spending most of her money on stationery and stamps. Letters were being sent to a variety of commercial, as well as private addresses. Only a small number of addressees contacted the hospital. In the light of Mrs W.'s deteriorating mental state and increasing agitation linked directly to delusional beliefs about the postal system and sending and receiving letters, and having taken legal advice, some material was withheld on the grounds that it would be in the interests of Mrs W.'s health to do so.

\section{Case three}

Mr D. was transferred to hospital from prison while on remand. He was facing a number of very serious charges. There was no evidence to suggest that he was actively mentally ill at the time of the alleged offences, but following his remand in custody he had become floridly psychotic. Mr D.'s mental state improved rapidly following his transfer to hospital. Some 2 weeks after being admitted to hospital he handed a letter to a member of nursing staff to be posted. The envelope was addressed to someone believed to have been an intended victim of one of the alleged offences, and below the address the words "we'll get you" were clearly written. Having taken legal advice, the letter was withheld and opened. It contained various threats and, as a consequence, the police were informed. This course of action was pursued in the interest of the safety of the alleged intended victim. The letter's contents might also have constituted or been linked with the commission of a criminal offence.

The steps taken in this case seemed appropriate in the light of the obvious potential for the letter to cause alarm, affect future criminal proceedings and in itself be part of a criminal offence either for sending a letter or article with intent to cause distress or anxiety under Section 1 of the Malicious Communications Act 1998 or witness intimidation under Section 51 of the Criminal Justice and Public Order Act 1995.

\section{Comment}

The three cases described above illustrate a variety of ways in which the matter of patients' mail, particularly outgoing postal packets, may become a medico-legal issue. None of these patients were detained in a special hospital and only one case involved the need to consider withholding incoming mail. They not only illustrate the use of Section 134 (1) (a) to withhold outgoing mail, but also dilemmas and potential difficulties that may arise where no statutory power is in place. Even in use of statutory powers there are obvious limitations in relation to the potential for breach of confidentiality. Although one may be aware that a member of the public may not wish to be receiving mail from a patient, one is placed in a particularly difficult position where the only means of making them aware of their rights under Section 134 of the Act might be to contact them by some direct means, which will inevitably involve an acknowledgement of the patient's situation and circumstances, compromising the clinician--patient relationship.

Provision for the inspection and withholding of postal packages for patients in special hospitals are potentially more intrusive but do allow for any concerns raised to be explored within the bounds of the statutory legal framework. This is not the case in other secure settings or locked facilities. This may lead to difficulties in dealing with situations where the clinical team are concerned that inappropriate material might be being sent into the hospital, for instance illegal drugs or weapons, or by patients out, such as details of the names and addresses of members of staff or other personal information.

As illustrated in case one, there may be circumstances where withholding incoming or outgoing mail might be deemed necessary in the patient's best interests. In these circumstances it is important to take appropriate legal advice before acting in this way, and essential to record any decision made and the reasons for it. It is vital to have discussed the situation fully with the patient and explain the reasons why mail is to be withheld.

In the case where the dispatch of a postal packet might actually or potentially constitute a criminal offence, such as in case 3, there may obviously be grounds for intervening. Again, this is best undertaken as a considered step and in consultation with the police. In addition, 
consideration may need to be given to whether mail should be passed to a third party.

It cannot be assumed that circumstances that justify the withholding of an incoming and outgoing postal packet also convey an automatic right to open and inspect its contents. As discussed earlier, Section 134 sub-section (4) does allow hospital managers to open and inspect any packet for the purposes of determining whether it can or should be withheld under the same Section. In all other cases, mail that is withheld should only be opened if it is likely that the information this provides is likely to have a significant bearing on the health or safety of others. Legal advice should always be sought before proceeding. If it transpires that the contents may have a potential bearing on public safety or risk to an identified individual, careful consideration must be given to how this information is handled, bearing in mind that confidentiality is not absolute and a duty to warn may arise. Lastly, Article 5 - the right to liberty and security of the person - and, more particularly, Article 8 - the right to respect for private and family life, home and correspondence - under the terms of the Human Rights Act 1998, will undoubtedly have an impact in these areas.

\section{References}

DEPARTMENT OF HEALTH AND WELSH JONES, R. (1999) Mental Health Act OFFICE (1999) Code of Practice. Mental Manual. London: Sweet \& Maxwell. Health Act 1983. London: Stationery Office.

GOSTIN, L. (1986) Mental Health Services - Law and Practice. London: Shaw \& Sons.

Luke Birmingham Senior Lecturer in Forensic Psychiatry, University of Southampton, *Martin S. Humphreys Senior Lecturer in Forensic Psychiatry, University of Birmingham, Reaside Clinic, Birmingham Great Park, Birmingham B45 9BE 